ARTIGOS

\title{
COACHING: UMA PONTE NO ABISMO RELACIONAL E GERENCIAL EM ORGANIZAÇÕES
}

\section{RESUMO}

Objetiva-se neste artigo conhecer as demandas das organizações apresentadas aos profissionais de coaching, visando atendimento focal para os gerentes seniores e juniores. Identificam-se poucas pesquisas nacionais que cunham o termo 'coaching' como aspecto central de seus trabalhos; sendo assim, há baixo volume de publicação e pouca profundidade científica no tema, que tem, em contrapartida, apelo no mercado nacional. Para este artigo opta-se pela metodologia qualitativa, com método exploratório. Foram entrevistados em profundidade dois profissionais de coaching, prosseguindo a análise por meio da técnica de análise de conteúdo por grade fechada. Conclui-se que o abismo entre gerentes seniores e juniores é tecnológico e vivencial. As organizações estão interessadas em amenizar as diferenças da construção de carreira de ambos profissionais, a fim de absorver suas competências diferencialmente, para equilibrar o desenvolvimento e manutenção das lideranças gerenciais, garantindo a produtividade, a lucratividade e a diversidade.

Rafaella Cristina Campos rafaella_ccampos@hotmail.com Doutoranda pela Universidade Federal de Lavras - UFLA. Mestre pela Universidade Federal de Lavras (UFLA). Psicóloga Bacharel pelo Centro Universitário de Lavras (UNILAVRAS)

Mônica Carvalho Alves Cappelle edmo@dae.ufla.br Doutorado em Administração pela Universidade Federal de Minas Gerais (UFMG). Professora associada do Departamento de Administração e Economia da Universidade Federal de Lavras (UNILAVRAS).

\section{Tayriane Mayre Silva} tayriane@live.com Graduanda em Administração pela Faculdade Presbiteriana Gammon - FAGAMMON.
Palavras-chave: Coaching. Organizações. Gerente Seniores. Gerentes Juniores.

\section{INTRODUÇ̃̃̃O}

A técnica de coaching é validada e amplamente utilizada desde o início dos anos 1980. Mas foi a partir do ano 2000 que houve o boom sobre o tema e sobre o processo/técnica no Brasil. Os motivos são diversos; vão desde os profissionais interessados em se capacitar como coaches, os clientes interessados em usufruir da técnica, interesse na característica extremamente focal do processo, e a expressividade social e financeira dada aos pertencentes à classe desses profissionais (RICH, 2015).

Há predominância do caráter democrático da formação do profissional de coaching, o que se torna um atrativo para pessoas com graduação (nas mais diversas áreas) ou sem graduação. Esta atratividade é também um ponto de atenção. Nota-se que há pessoas que não se desenvolvem com profissionalismo e ética após a conclusão do curso e prostituem a técnica com marketing apela- 
tivo e promessas falsas aos coachees $(\mathrm{RICH}$, 2015; CARDOSO et al., 2012).

Além da identificação de demandas de pessoas interessadas em ser os profissionais de coaching, e pessoas que querem ser coachees, há também interesse das organizações, que manifestam demanda distinta: buscar equilíbrio nas relações entre os seus colaboradores, especialmente os que estão em cargos gerenciais e/ ou estratégicos (CARDOSO et al., 2012).

O coaching é um processo direcionado por uma demanda específica, com foco em metas e resultados de curto, médio e longo prazos, visando ao vislumbramento do positivo e empoderamento total do coachee no processo de desenvolvimento. Sendo assim, busca-se este processo para construir uma ponte nos abismos relacionais e gerenciais dentro das organizações, abismo que é o resultado da convivência dos gerentes seniores e juniores (CARDOSO et al., 2012; LIMA; CARVALHO NETO; TANURE, 2012).

Destaca-se que dada complexidade das relações humanas e estruturas organizacionais, não há como falar da diversidade de profissionais em cargos gerenciais sem esbarrar e atribuir características geracionais. A conduta mediante o trabalho e a vida (relações) são distintas e próprias de cada geração, construídas por processos sócio-histórico-culturais diferenciados. Mesmo que imersos numa mesma constituinte micro social. As organizações têm dificuldade em absorver destes dois profissionais, os gerentes seniores e juniores, o melhor de ambos - respectivamente, experiência e inovação - sem gerar competitividade destrutiva, desenvolvendo a liderança e a criatividade no contexto organizacional (LIMA; CARVALHO NETO; TANURE, 2012).

A contextualização acima aponta que, dentro das organizações, há necessariamente a convivência entre profissionais de diversas gerações. Nos cargos gerenciais esta convivência é desiquilibrada pelas características da historicidade de formação e vivencial que há entre os gerentes seniores e juniores, bem como diferenças em seus objetivos profissionais e pessoais. Tendo em vista este cenário, pergunta-se: como as organizações têm-se preparado para absorver o melhor dos gerentes seniores e juniores, buscando o equilíbrio relacional e gerencial entre eles?

O objetivo principal deste artigo é conhecer as demandas das organizações apresentadas aos profissionais de coaching, visando ao atendimento focal para os gerentes seniores e juniores.

Para os objetivos específicos define-se 2(dois): o primeiro é averiguar quais são as características relacionais entre os gerentes seniores e juniores; o segundo é compreender quais são as características gerenciais dos gerentes seniores e juniores.

Justifica-se a condução da pesquisa por sua contribuição teórico-prática, que propõe a compreensão do coaching não só como técnica, mas também como aparato necessário para auxiliar no desenvolvimento de um equilíbrio relacional e gerencial entre os gerentes seniores e juniores. Nota-se que não há publicações de cunho científico no vasto acervo eletrônico no Brasil, ao procurar através da palavra 'coaching' na base de indexação SCIELO, somente 2(dois) artigos completos foram encontrados que estão com a temática diretamente relacionada à técnica/processo de coaching.

Esta escassez denota ao coaching uma aproximação marginal e superficial nas pesquisas acadêmicas. Este esquecimento que há na academia é um contraponto do interesse mercadológico que há pela busca do domínio da técnica. Há cada vez mais cursos e profissionais capacitados (ou não) para oferecer tanto a técnica quanto a formação no mercado brasileiro. A realidade destacada neste artigo - busca pelo equilíbrio relacional e gerencial entre gerentes seniores e juniores - é mais que a exploração da técnica, trata-se de uma tentativa pela busca da compreensão de um movimento social e mercadológico, que é o coaching na atualidade brasileira.

Para a construção deste artigo, foram subdivididas cinco sessões. A primeira sessão trata da contextualização e introdução ao tema, a se- 
gunda sessão é uma discussão do acervo teórico encontrado que reflete diretamente no tema e objetivos deste artigo. Logo após, há a descrição metodológica que foca na pesquisa qualitativa de método exploratório com duas entrevistas em profundidade, seguida das análises elaboradas por meio da técnica de análise de conteúdo e finalizando com a conclusão.

Após a apresentação das sessões deste artigo, seguem abaixo as reflexões sobre o referencial teórico selecionado.

\section{DISCUSSÃO BREVE E HISTÓRICA SOBRE A ORIENTAÇÃO PROFIS- SIONAL, MENTORING E COA- CHING NO CONTEXTO ORGANI- ZACIONAL}

A orientação profissional origina-se em 1902 na Alemanha, com o intuito de evitar os acidentes de trabalho que eram frequentes, e por vezes, com resultados de mortalidade. A transição entre a orientação profissional como ferramenta de monitoramento para instrumento de análise e desenvolvimento nas organizações foi gradual e, apesar de ter nascido na Alemanha, foi nos Estados Unidos nos anos 1980 que ganhou formato personalizado e focado nos objetivos planejamento profissional dos colaboradores de uma organização (SPARTA, 2003).

Entre os anos de 1980, o foco passou a ser atendimento às empresas para classificar os candidatos como aptos ou inaptos a determinadas funções, tornando-se de caráter excludente, como o próprio trabalho já era, e ainda é. As origens dos procedimentos de orientação profissional surgiram no contexto organizacional, primordialmente para atender as demandas de melhoria na produtividade e assertividade na distribuição de postos de trabalho (SPARTA, 2003).

No período dos anos 2000, a orientação profissional passou a ter foco nos candidatos e colaboradores das empresas, visando auxílio na descoberta e no desenvolvimento de habilidades pessoais e profissionais que permitisse satisfação do colaborador com seu trabalho. A orientação profissional com foco no colaborador é recente, e mesmo assim, não se desvincula das preocupações organizacionais (GUEIROS, 2009).

Tanto para atender aos colaboradores/ candidatos, quanto para atender às organizações, a orientação profissional sofre influência em modelos positivistas, isso porque a seu cerne na psicologia alemã e norte americana é de base estatística, provendo então concentração dos esforços na produção de mais inventários e testes do que na busca do conhecimento do processo de vivência para o sujeito (NORONHA; AMBIEL, 2006).

O processo de orientação profissional precisa de uma dose de objetividade, mas uma dose apenas, não uma determinação sumária de que os testes e inventários são a resposta ou o caminho final, de uma atividade que é um processo integralista e cíclico. Sendo assim, ainda no período do início dos anos 2000, a orientação profissional começa a caminhar pelo rumo da customização dos atendimentos e do processo, visando a quebra do paradigma e das práticas ligadas estritamente ao objetivismo, mas utilizando-o para aprofundar nos aspectos subjetivos (MELO-SILVA; LASSANCE; SOARES, 2004).

Permanece a crescente demanda para o aperfeiçoamento dos processos de orientação profissional. Isso porque o número de opções de escolha profissional e de exercício do trabalho se multiplicam e se transformam, devido ao acesso a informações que ampliam a gama de possibilidade de escolhas, mas não há avanço significativo no movimento social de autoconscientização das habilidades, condições sócio culturais e subjetivas para de fato fazer uma escolha e um investimento na vida profissional, e por consequência na vida pessoal (SPARTA; BARGADI; TEIXEIRA, 2006).

Com a demanda crescente de público adepto da orientação profissional, note-se uma pressa na evolução do processo. Retoma-se que a vivência do processo de orientação profissional é tão importante quanto o resultado, mas como a dinâmica e as exigências do contexto corporativo buscam demandam de uma agilidade, há que se questionar a multiplicidade astro- 
nômica de atividades e processos que surgiram na última década (LASSANCE, 2006).

A orientação profissional tem e precisa ser objetiva, no sentido de que trabalha um objetivo focal, mas não quer dizer que deve restringir o processo a inventários e testes. Com a necessidade de se promover uma orientação profissional mais diretiva e mais vivencial do que demonstrativa, novas técnicas surgem tentando suprir este gap. Entre muitos recursos utilizados, ressaltam-se como os mais emergentes e com maior demanda nas organizações: mentoring e coaching (RICH, 2015).

$\mathrm{O}$ processo de mentoring é guiado pelo exemplo e pela experiência de um profissional já com carreira estabelecida na área em que o novo profissional quer ingressar. O mentoring não trabalha com modelos de atendimentos, mas sim, com a transmissão de conhecimento pessoal e profissional transmitido de um admirado para um admirador (JUER; SANTOS; SANTOS, 2009).

$\mathrm{O}$ mentoring surgiu para treinar líderes e aspirantes a líderes por meio do exemplo, estimulando quem chega recentemente na carreira e também, quem está nela há algum tempo. No mentoring estão envolvidos um mentor, um aprendiz e a troca da experiência pelo caminho já trilhado e pela ansiedade de chegar até lá (GUEIROS, 2009, 2012).

O processo de mentoring é utilizado pelas empresas, que desejam fazer a troca de informações entre gerentes juniores, cheios de anseios, planos e falta de experiência, e gerentes seniores, que já passaram por experiências desafiadoras no mercado trabalho e buscam modernização na forma de agir e pensar o trabalho. A ideia da mentoria é desenvolver um novo profissional por meio do espelhamento com outra pessoa com mais experiência, e fazer com que o mentor se motive ao ensinar e nesta troca aprender mais com uma geração mais nova (CAMPOS; CAPPELLE; BAETA, 2016).

Já o processo de coaching consiste na avaliação das características pessoais e profissionais a fim de se encontrar um "chamado" para o exercício da profissão. O coaching é um processo em que se guia a descoberta das habilidades por meio de estabelecimento de metas de curto, médio e longo prazo (REIS, 2013).

O processo de coaching é mais diretivo, com foco no positivo, nas experiências de vida que levam ao indivíduo a ser o que ele é hoje e nas expectativas que ele tem de si em um futuro próximo e distante. O processo para ser desenvolvido depende muito do envolvimento do coachee. Esta exigência é parte primordial da elaboração do coaching. Responsabilizar-se pela tomada de decisão e ter autonomia são as tarefas principais no desenvolvimento de coaching (PEREIRA; SILVA, 2011).

Há diferenciações entre mentoring e coaching que vão além da aplicabilidade de cada método. O mentoring pode ser caracterizado como um treinamento interno de baixo o nenhum custo financeiro para a organização. Em contrapartida, o coaching demanda um alto investimento financeiro da empresa. Além disso, o mentoring é uma via de mão dupla, em que tanto o mentor quanto o aprendiz são ativos no processo de ensino e aprendizagem. Já o coaching demanda distanciamento do coach para o coachee, caracterizando um atendimento, não um treinamento (JUER; SANTOS; SANTOS, 2009; PINTO; TAVEIRA, 2013).

Tanto o mentoring quanto o coaching, surgem na emersão do paradigma de escolha profissional atual. Se antes quando o trabalho era estratificado o dilema era como sair de algo já previsto ou aprimorar o ofício hereditário, hoje, a dificuldade entre os profissionais está em lidar com a gama de possibilidades que lhes é exposta, e ainda, conviver com a elaboração subjetiva do que a sua profissão e trabalho devem representar para si (SOUZA; SCORSOLINI-COMIN, 2011).

Segue abaixo uma ilustração demonstrativa da busca das organizações por processos de orientação profissional a fim de lidar com as diferenças emergentes entre gerentes seniores e juniores. 


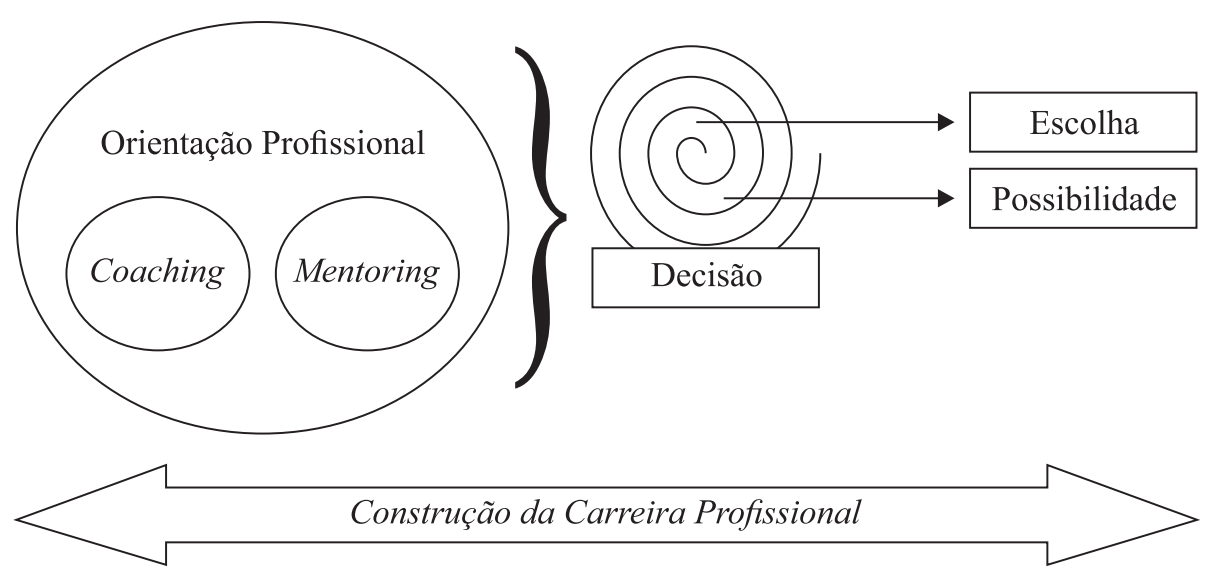

Figura 1- Demonstração da Relação Entre a Orientação Profissional no Contexto Organizacional o Movimento de Tomada de Decisão Individual

Fonte: elaborado pelas autoras (2016).

Tendo em vista o desenvolvimento dos processos de orientação profissional no contexto organizacional, destaca-se a emergência dos aspectos relacionais e gerenciais dos gerentes seniores e juniores, ressaltado na introdução deste artigo. Os processos de mentoring e coaching são buscados pelas organizações para eliminar ou amenizar o abismo que existe nas práticas e vivências dos profissionais de gerações diferentes.

Lembrando que a tomada de decisão na construção da carreira é um movimento cíclico, dinâmico e constante na vida do sujeito, não há como pensar em processos de orientação profissional que sejam estagnados e estáticos, uma vez que o próprio ser humano não o é, mas algumas diretrizes são necessárias e possíveis para guiar o processo que demanda de um resultado pontual.

\section{METODOLOGIA DE PESQUISA}

O objetivo principal deste artigo é conhecer as demandas das organizações apresentadas aos profissionais de coaching, visando ao atendimento focal para os gerentes seniores e juniores. Para tanto, define-se como a natureza deste artigo sendo qualitativa, a qual permite que sejam enaltecidos neste artigo aspectos de compreensão, reflexão e discussão, derivados da perspectiva subjetiva (RAMPAZZO, 2005).

Partindo da perspectiva qualitativa, opta-se pelo método exploratório, que visa à compreensão de fenômeno social que se considera recorrente em diversas realidades, mas com diversas manifestações e com uma relação de causalidade ainda inexplicável. Sendo assim, o método exploratório visa compreender uma realidade focada, mas nesta prevê-se a possibilidade de expansão (RAMPAZZO, 2005).

Delimita-se então tanto a metodologia qualitativa quanto o método exploratório, há que se definir agora os procedimentos metodológicos. Opta-se pela entrevista em profundidade, realizada com 2 (dois) profissionais de coaching.

A técnica de entrevista em profundidade não visa volume de dados captados, mas sim, aprofundamento em poucas questões que vislumbrem o fenômeno estudado, seja ele qual for (FONTANELLA; CAMPOS; TURATO, 2006). A técnica de entrevista em profundidade foi selecionada para atender a uma dificuldade desta pesquisa: a dificuldade de encontrar profissionais de coaching que estivessem disponíveis a tratar dos objetivos desta pesquisa, sem vínculo lucrativo.

Foram contatados para a participação efetiva da pesquisa que resultou neste artigo 2(dois) profissionais de coaching, atuantes nas vertentes de Life Coaching (Coach 1) e Coaching Vocacional (Coach 2), formados, 
respectivamente, nas escolas Condor Blanco e no Instituto Brasileiro de Coaching (IBC). A formação básica de ambos os profissionais que se dispuseram a participar desta pesquisa é psicologia. $\mathrm{O}$ critério para a inclusão de participantes na amostra foi atender às organizações e colaboradores em cargos de gestão e/ou estratégicos. Esse critério se faz válido uma vez que a realidade e a demanda das organizações para o profissional de coaching é plural, desejando-se para o cumprimento dos objetivos uma visão ao mesmo tempo sistêmica e focal do fenômeno relacional e gerencial de gerentes seniores e juniores.

Não houve vínculo financeiro para a realização da pesquisa que resultou neste artigo. Ambos os participantes assinaram o Termo de Consentimento Livre e Esclarecido (TCLE) garantindo o sigilo de suas identidades, bem como a segurança de interrupção e suspensão da pesquisa, caso achassem necessário. $\mathrm{O}$ TCLE garante que os critérios éticos da coleta e análise dos dados sejam criteriosamente condu- zidos, evitando qualquer constrangimento para os envolvidos na pesquisa, e principalmente, caráter ético e responsável dos pesquisadores.

Após a coleta de dados por meio da entrevista em profundidade, define-se que para o tratamento dos dados é viável a utilização de técnica de análise de conteúdo por grade fixa. A análise de conteúdo consiste na técnica capaz de detectar frequências de similaridade e diferenciações nos relatos dos entrevistados, buscando a compreensão do fenômeno estudado (RAMPAZZO, 2005).

Para realizar a análise de conteúdo há divisão de dois blocos de análises, cada um correspondente a um objetivo específico, por isso, a caracterização da grade fixa, ou seja, as análises vão tratar dos fragmentos de falas das entrevistas em profundidade que vão responder aos objetivos deste artigo de forma direta. Para efeito didático, segue abaixo uma tabela que mostra a relação entre os objetivos específicos e as categorias de análises de dados.

Tabela 1- Relação entre os Objetivos Específicos e as Categorias de Análise de Dados

\begin{tabular}{l|l}
\hline OBJETIVOS ESPECÍFICOS & $\begin{array}{l}\text { CATEGORIAS DE ANÁLISES DE DADOS POR } \\
\text { GRADE FIXA (TÍTULOS) }\end{array}$ \\
\hline $\begin{array}{l}\text { Averiguar quais são as características relacionais } \\
\text { entre os gerentes seniores e juniores. }\end{array}$ & $\begin{array}{l}\text { "A Demanda Relaciona: Os Antigos querem se } \\
\text { 'Modernizar', e os Jovens Devem Aprender a } \\
\text { Desacelerar." }\end{array}$ \\
\hline $\begin{array}{l}\text { Compreender quais são as características gerenciais } \\
\text { dos gerentes seniores e juniores. }\end{array}$ & $\begin{array}{l}\text { "A Demanda Processual: Turbulência entre a } \\
\text { Cautela da Experiência e a Pressa da Inovação". }\end{array}$ \\
\hline
\end{tabular}

Fonte: dados da pesquisa (2016).

Após a relação entre os objetivos específicos e as categorias de análise de dados, seguem abaixo, os achados empíricos deste artigo.

\section{COACHING, A BUSCA PELO EQUILÍ- BRIO E PELA CONGRUÊNCIA: RE- FLEXÃO SOBRE OS RESULTADOS}

Apesar da crescente demanda de trabalho, o profissional de coaching enfrenta problemas com relação ao reconhecimento e regulamentação da profissão, dificultando a ampliação de suas técnicas e um alcance maior da população ao profissional, dificuldades que remetem à discussão realizada na introdução deste artigo, em que se levou em consideração a democracia do acesso à formação para ser coach como aspecto benéfico e maléfico (REIS, 2013).

Então assim, que formação que essa pessoa está tendo? Uma pessoa que faz isso, e escreve até errado o nome da profissão em que ela está atuando, e ouve uma pessoa que sai de uma sala de atendimento e vai comentar isso com outra pessoa que está ali de fora, que ética essa pessoa está tendo? (Coach 1$)$. 
Os entrevistados relatam que o coach, apesar de ter mais espaço representatividade no mercado de trabalho na atualidade, ainda tem suas práticas mal compreendidas e disseminadas. Esta situação pode ser derivada da falta de amarrações éticas à profissão (não é reconhecida no Brasil). Se um coach é anteriormente administrador, psicólogo, médico, contador, seja lá qual for sua formação no ensino superior, ele terá um código de ética a seguir, e punições caso não o faça. Mas se o coach que não tem uma formação superior anterior, não há designação ou punição formal de diretrizes éticas; há falhas consequentes deste acesso indiscriminado da população ao coaching.

De acordo com os coaches, todas as demandas que chegam a eles giram em torno de uma mesma temática: como lidar com o sofrimento? Tanto para os gestores seniores, que lidam com uma dinâmica de mercado cada vez mais ágil e miscigenada, quanto para os jovens gestores, que chegam ao topo de suas carreiras muito rápido (CAMPOS; CAPPELLE; BAETA, 2016). "A maioria das pessoas que chegam ainda é com certo sofrimento, tipo quero largar tudo não tô aguentando mais o que tô fazendo e fiquei sabendo que você." (Coach 2).

O sofrimento é inerente ao mundo do trabalho. Mesmo satisfeito na empresa e com as atividades do dia a dia, o ato de trabalhar exige adaptabilidade e mobilidade constantes. Há que se destacar aqui que adaptar às rotinas de trabalho é também adequar-se às relações estabelecidas neste trabalho, as quais, mesmo bem definidas, são diariamente rearranjadas.

Na busca pela compreensão deste esforço de equilíbrio relacional nas organizações, seguem abaixo as discussões sobre os dados encontrados, levando em consideração a realidade dos coaches ao trabalharem com gerentes seniores e juniores.

\subsection{A DEMANDA RELACIONAL: OS ANTIGOS QUEREM SE 'MODER- NIZAR', E OS JOVENS DEVEM APRENDER A DESACELERAR}

De acordo com os coaches entrevistados, a principal demanda dos gestores seniores é lidar com habilidades que permitem a administração de informações. Acostumados a realizar processos nas empresas da mesma forma há muito tempo, e com sucesso, este encontro com uma nova geração repleta de aparatos eletrônicos e com uma dinamicidade de dar e receber informações, mas nem sempre filtradas, os antigos gestores têm dificuldade de lidar com este dinamismo e para isso procuram o profissional de coaching.
Olha você não tem ideia do que o so- frimento desse pessoal de empresa que não quer sair de jeito nenhum, mas não consegue acompanhar as no- vidades, sabe. Teve um que veio aqui uma vez que comprou um 'Itudo' que você pode imaginar, queria aprender de qualquer jeito. Acho que o pior para eles é sentir esse processo de substituição; sabe, antigamente não se podia ensinar aos sucessores senão você perdia o emprego; hoje se você não ensina para os novos com sua experiência, fica difícil terminar bem a vida profissional. Nossa, o pessoal vem aqui sofre e com isso. Lidar com o novo sabe. (Coach 2).

Com o fragmento acima, avalia-se que o sofrimento está no centro do relato, mas que a ligação entre os antigos e novos gerentes pode-se fragilizar pela forma diferenciada da construção de carreira dos dois atores.

Apesar dos tipos de experiência serem por si só muito diferentes, os recrutadores construíam o conhecimento dentro do trabalho, já os recém-formados que se tornam gerentes chegam já num cargo tático sem nem ter trabalhado em outros cargos de baixa hierarquia na empresa atual, o que pode intimidar os recrutadores tanto na hora de recrutar, quanto na hora de manter os novos talentos.

As gerações dos anos de 1960 e 1970 foram criadas em um mundo de falta de opção e por isso sua capacitação ocorreu de acordo com a necessidade e não com a oportunidade. Construindo uma carreira em que se controlavam as informações e a comunicação, em que 
não havia cumplicidade entre as atividades e os processos como é hoje, dificulta a quebra de resistência com o novo (ABRAHIM, 2008; REIS, 2013).

Os gerentes seniores não tinham opções diversas na formação superior. No contexto de formação profissional e pessoal deles, o trabalho era visto como uma necessidade inerente à sua vontade; então, o desenvolvimento da adaptação e da capacidade colaborativa era instintivamente evoluído na relação com o trabalho e com a empresa. As empresas em que trabalhavam, por vezes, ofertavam as chances para a capacitação no ensino superior, mas já focado na experiência que o colaborador tinha e na capacidade de absorção que a própria empresa teria ao estimular o estudo daquele colaborador e futuro gerente (AMARAL et al., 2012; CAMPOS; CAPPELLE; BAETA, 2016).

Já os gerentes juniores têm uma vasta opção na formação superior, podendo direcionar sua capacitação profissional e pessoal para cargos de gerência sem necessariamente ter que fazer cursos clássicos na área gerencial, como administração ou pedagogia por exemplo. Além disso, os novos gerentes percebem a capacitação superior como um direito, não como um privilégio, encarando com alto grau de competitividade o desenvolvimento de sua carreira profissional (SCHEIBLE; BASTOS; RODRIGUES, 2013; SILVA; TAVEIRA; RIBEIRO, 2009).

A consequência direta da adequação mediante as oportunidades que os gerentes seniores têm, e o desenvolvimento de oportunidades mediante a formação que os gerentes juniores têm, faz que dentro do ambiente organizacional ocorra uma dicotomia entre adaptabilidade e experiência e a modernização e a pressa. "Olha, empresa quer resultados, não é? Muitos gestores vêm aqui por indicação da empresa mesmo; sabe o que a gente procura muito fazer? Fazer a ponte entre experiência e agilidade, cada um dando o que pode e sabe." (Coach1).

$\mathrm{O}$ relato acima explicita por que as empresas estão atentas ao gap relacional, e por consequência o gerencial (estratégico) que há entre os gerentes seniores e juniores. Se, além da percepção das organizações, há também a busca pela resolução deste encontro dos gerentes, nota-se que é vital o estabelecimento de uma boa relação entre ambos para, somente assim, haver lucratividade financeira e interpessoal no contexto empresarial.

Há, na literatura leiga (revistas de circulação) apontamentos do movimento de 'substituição', e os relatos desta pesquisa indicam o contrário, que há, tanto nas empresas quanto para os gerentes seniores e juniores o interesse de estabelecer uma boa dinâmica relacional para absorver ao máximo e melhor de ambas as carreiras gerenciais.

Pode-se, então, concluir parcialmente que a busca dos gerentes seniores pela modernização, e a busca dos gerentes juniores pelo desaceleramento é um movimento congruente para garantir o alcance da boa convivência organizacional, sendo as empresas, aderentes à captação e permanência da experiência dos profissionais mais antigos e do instinto ágil e inovativo dos novos gerentes.

\subsection{A DEMANDA PROCESSUAL: TUR- BULÊNCIA ENTRE A CAUTELA DA EXPERIÊNCIA E A PRESSA DA INOVAÇÃO}

De acordo com os profissionais de coaching entrevistados, os gerentes seniores e juniores buscam o processo de coaching por razões distintas, sendo elas respectivamente: desenvolvimento de habilidades comportamentais que permitam o acompanhamento da tecnologia e da busca por inovação e do desaceleramento do processo de construção de carreira.

Os recém-formados gerentes alcançam o ápice de sua carreira profissional ainda inexperientes em vivência no trabalho e organizacional. Os profissionais de coaching entrevistados traçam o perfil dos gerentes juniores: eles não estão dispostos a fazer parte de qualquer ambiente de trabalho; são ágeis no raciocínio, estão dispostos - pelo menos incialmente - a abrir mão da vida pessoal para desenvolver a 
vida no trabalho e são focados na inovação, por vezes, negligenciando a fala da experiência dos profissionais mais antigos e falta-lhes paciência para aguardar as movimentações espontâneas na empresa, como promoção de cargo e melhoria nas condições de trabalho. "O que dá pra perceber é assim, esse pessoal mais novo é muito disposto a trabalhar, mas não quer trabalhar de qualquer jeito, sabe?! Eles querem viajar, estar em cargos cada vez mais altos, têm pouca ética, isso para quem é mais velho na empresa é um problema." (Coach 1). "Porque o sofrimento delas, ela já chegou naquele ponto assim, 'eu optei por ser feliz, não quero mais, não quero viver do jeito que eu tava vivendo'; então essa dor ela é também, ela é muito transformadora." (Coach 2).

Mesmo tendo alcançado o objetivo almejado na graduação de chegar a um cargo de gestão, os gerentes juniores procuram se acalmar, para que a ansiedade não domine a vontade de crescer ainda mais. Por terem ingressado no mercado de trabalho com cargos de alta hierarquia, a vontade de crescer e rápido muitas vezes pode atrapalhar a construção da carreira. Mas os gerentes juniores buscam pelo desaceleramento, uma vez que a vida organizacional está comprometida na relação com colaboradores mais antigos; se isso não acontece, os profissionais de coaching entrevistados dizem que a pressa é vista como uma qualidade, então os novos gerentes não buscam baixar as expectativas, mas sim, aumentá-las ainda mais.

O conflito de sentimento é uma questão emergente que os recém-formados levam aos profissionais de coaching. $\mathrm{O}$ anseio de construir suas carreiras chega a ser um peso tão grande que eles questionam, mesmo tendo atingido seus objetivos, se tudo realmente é o que eles queriam e almejavam.

Esses novos gerentes novinhos aí a crise (nome da entrevistadora), a crise que eles enfrentam sabe porque eles acham que são imunes ao erro, sabe. Eles chegam aqui como se tivesse fazendo entrevista de emprego sabe, querem destacar tudo que eles tem de bom e aí a gente já percebe o tamanho da dor. O medo da queda 'neh' [...] Porque eles não estão acostumados a levar as coisas com calma, a depender de outros fatores para ter o que eles querem, muitos vêm aqui tentando aprender a como escutar sabia. Mesmo o pessoal bem profissionalmente sabe. (Coach 1).

O fragmento acima mostra que a dificuldade dos recém-formados não é exercer a função do cargo, mas lidar com suas carreiras que ascenderam rápido em relação aos antigos gerentes, que fazem parte do corpo da empresa em que trabalham. Crescer na carreira também é um fator de sofrimento para os novos gerentes, porque é dali pra frente, o que eles querem e o que vão fazer fica nebuloso. A pressa é inimiga dos melhores gerentes desta geração (VELOSO; DUTRA, 2011; VELOSO; DUTRA; NAKATA, 2016).

De acordo com as análises acima, é possível determinar que apesar de estarem bem colocados no mercado de trabalho e terem conquistado seus objetivos, os recém-formados gerentes tem dificuldade de lidar com as questões de perspectiva futura, de saber lidar com o presente de desacelerar.

Por isso, o coaching ficou popular para a geração dos antigos gerentes. Apesar de ser uma atividade firmada no mercado há muito tempo, a geração baby boomers popularizou o atendimento pelo estilo de atendimento voltado para um período breve de transformações da ação principal e de longo prazo para manutenção (VELOSO; DUTRA, 2011; VELOSO; DUTRA; NAKATA, 2016).

\section{CONCLUSÃO}

O objetivo principal deste artigo foi conhecer as demandas das organizações apresentadas aos profissionais de coaching, visando ao atendimento focal para os gerentes seniores e juniores. A demanda dos gestores seniores é focada na adaptabilidade de um contexto cada vez mais informatizado e com convivência 
com o público jovem, que não tem fidelidade à empresa como objetivo principal de carreira, que no ponto de vista dos gestores mais antigos beira à falta de ética. $\mathrm{O}$ receio da substituição é uma ansiedade constante que conflita com a gestão da empresa bem como com a convivência com os novos egressos.

As demandas dos gestores juniores é a busca da conquista rápida e astronômica da carreira gerencial, os recém-formados querem o que no ponto de vista deles é um direito diante do esforço requerido na formação acadêmica, e isto ocasiona uma ansiedade que se contrapõe à cautela da experiência dos gestores mais experientes. Os novos gestores querem o que consideram melhor para si e isso gera instabilidade no processo gerencial, dado que os gestores seniores têm uma relação de 'gratidão' com a empresa, já os gestores juniores têm uma relação de gratidão entre si.

Nota-se com o desenvolvimento deste artigo que a busca pela compreensão do processo de coaching no universo acadêmico ainda é comedida. As pesquisas acadêmicas vêm avançando, mas ainda são marginalizadas.

Pode-se concluir com a análise dos relatos acima que apesar da construção de carreira e de vida e das percepções entre os antigos e novos gerentes serem distintas, o medo que os une e guia para a busca do processo de coaching é o mesmo: o temor de serem substituídos e, além disso, o receio de não dar conta das atividades a serem desempenhadas em um cargo de gerência, o que é contraditório, uma vez que ambos buscaram a alta colocação no mercado de trabalho, o que mostra uma fragilidade, mascarada pela hierarquia organizacional.

Sugere-se que, para as pesquisas futuras, sejam entrevistados em profundidade mais profissionais de coaching e como eles percebem sua contribuição dentro e fora do contexto organizacional. Sugere-se uma pesquisa comparativa na formação anterior a de capacitação em coaching que os coaches têm, seria uma pesquisa que contribuiria para a compreensão da busca pela formação e também da contribuição que a formação anterior teve no profissional coach.
Destaca-se a importância do critério ético e crítico da formação em coaching, uma vez que a democratização ao acesso pode ser benéfica pela competitividade, mas também maléfica, sendo que qualquer pessoa pode capacitar-se na área e não ter insight, know how ou até mesmo feeling para lidar com as demandas relacionais que surgem no trabalho de coaching.

\section{COACHING: A BRIDGE IN THE RELATIONS AND MANAGEMENT ABYSS IN ORGANIZATIONS}

\section{ABSTRACT}

The main goal of this article is to determine the demands of the organizations that seek coaching professionals to tend to the needs of senior and junior managers. We identified very few national researches on the topic that establish coaching as the main aspect of the papers; therefore, there is a small number of publications and little scientific depth on the subject, which has, on the other hand, large appeal in the national market. We chose a qualitative methodology for this article, with an exploratory method. Two in-depth interviews with coaching professionals were conducted, and the data analysis also included content analysis by closed grid. We concluded that the abyss between senior and junior managers is both technological and experiential. The organizations are interested in diminishing the differences in the career development of both groups of professionals, so as to benefit from their different competencies, to balance the development and the maintenance of management leaderships, thus ensuring productivity, profitability and diversity.

Keywords: Coaching. Organizations. Senior Managers. Junior Managers. 


\section{COACHING: UN PUENTE EN EL ABISMO RELACIONAL Y GERENCIAL EN ORGANIZACIONES}

\section{RESUMEN}

Se objetiva en este artículo conocer las demandas de las organizaciones que se presentan a los profesionales de coaching para atención focal para los gerentes séniores y júniores. Se identifican pocas investigaciones nacionales que establecen el término coaching como aspecto central de sus trabajos; así, hay bajo número de publicaciones y poca profundidad científica en el tema, que tiene, en contrapartida, apelo en el escenario nacional. Para este artículo, se opta por la metodología cualitativa, con método exploratorio. Fueron entrevistados en profundidad dos profesionales de coaching, prosiguiendo el análisis a través de la técnica de análisis de contenido por redes cerradas. Se concluye que el abismo entre gerentes séniores y júniores es tecnológico y vivencial. Las organizaciones están interesadas en disminuir las diferencias de la construcción de carrera de ambos los grupos de profesionales, para que pueda beneficiarse de sus diferentes competencias, para equilibrar el desarrollo y la manutención de los liderazgos gerenciales, garantizando la productividad, la rentabilidad y la diversidad.

Palabras-clave: Coaching. Organizaciones. Gerentes Séniores. Gerentes Júniores.

\section{COACHING: UN PONT SUR L'ABIME RELATIONNEL ET ADMINISTRATIF DANS DES ORGANISATIONS}

\section{RESUME}

L'objectif de cet article est d'établir le demandes des organisations qui se présentent aux professionnels de coaching pour demander un service spécialisé pour les gérants seniors et juniors. Nous avons identifié peux de recherches qui établissent le terme coaching comme un aspect central de leurs travaux, ainsi, il y a un nombre de publications et peu de profondité scientifique sur le sujet, qui fait, en contrepartie, appel sur la scène nationale. Pour cette article, nous avons choisi la méthodologie qualitative, avec une méthode exploratoire. Nous avons interviewé deux professionnels de coaching, et poursuivi l'analyse des données à travers la technique d'analys de contenu par grille fermée. Nous avons conclu que l'abîme entre les gérants seniors et juniors est tecnologique et existentiel. Les organisations s'intéressent à la diminution des différences dans la construction de carrières des deux groupes professionnels, à fin de ce qu'elle puisse absorber leurs différentes compétences, pour équilibrer le développement et la manutention des leaderships gérantielles, ce que garantit la productivité, la rentabilité et la diversité.

Mots-clés: Coaching. Organisations. Gérants seniors. Gérants juniors.

1 Este artigo é parte dos resultados da dissertação de mestrado da primeira autora, sob a orientação da segunda autora. O projeto que originou a pesquisa foi submetido ao Comitê de Ética com Seres Humanos na Universidade Federal de Lavras - COEP/UFLA - e foi aprovado com o registro CAAE: 1932.1613.7.0000.5148.

2 A palavra 'geração' tem uma definição e origem sociológica, caraterística forte dos estudos norte-americanos, e será usada no decorrer deste artigo para explicitar as diferenças vivenciais, de formação e conduta que há entre os gerentes sêniores e juniores. Não há, portanto, o emprego deste termo como cunho conceitual, é apensar uma 'palavra' utilizada para explicitar que há dois tipos de profissionais advindos de uma historicidade particular, ocupando cargos num mesmo escalão hierárquico.

\section{REFERÊNCIAS}

ABRAHIM, Gisele Seabra. O papel dos valores pessoais nas decisões de carreira. Contextus: Revista Contemporânea de Economia e Gestão, Fortaleza, v. 6, n. 2, p. 35-44, 2008.

AMARAL, Iraldes Gonçalves do et al. Carreira, mercado de trabalho e as lições de "Donana" 
no processo de ensino aprendizagem e pesquisa em Administração. Revista Eletrônica de Ciência Administrativa (RECADM), Paraná, v. 11, n. 1, p. 95-114, 2012.

CAMPOS, Rafaella Cristina; CAPPELLE, Monica Carvalho Alves; BAETA, Odemir Vieira. Explorando a construção da carreira gerencial: as relações e interações entre gerente seniores e juniores. In: SEMINÁRIO DE GESTÃO ORGANIZACIONAL CONTEMPORÂNEA, 9., 2016, Vitória. Anais... Vitória: UFES, 2016.

CARDOSO, Paulo Miguel et al. Psychologists' dilemmas in carrier counselling practice. International Journal of Education and Vocational Guidance, Netherlands, v. 12, n. 9, p. 225-241, 2012.

FONTANELLA, Bruno José Barcellos; CAMPOS, Claudinei José Gomes; TURATO, Egberto Ribeiro. Coleta de dados na pesquisa clínico-qualitativa: uso de entrevistas não dirigidas de questões abertas por profissionais de saúde. Revista Latino Americana de Enfermagem, São Paulo, v. 14, n. 5, p. 1-10, 2006.

GUEIROS, Mônica Maria Barbosa. As funções da mentoria como um instrumento de apoio ao desenvolvimento profissional dos dirigentes de faculdade de ensino superior. In: ENCONTRO DA ANPAD, 33., 2009, São Paulo. Anais... São Paulo: Anpad, 2009.

GUEIROS, Mônica Maria Barbosa. Um estudo sobre a rede de relações de desenvolvimento profissional construídas pelos dirigentes em organização familiar. In: ENCONTRO DA ANPAD, 36., 2012, Rio de Janeiro. Anais... Rio de Janeiro: Anpad, 2012.

JUER, Mariana; SANTOS, Neusa Maria Bastos Fernandes; SANTOS, Roberto Fernandes dos. Mentoria: um estudo das expectativas de mentores e mentoreados. In: ENCONTRO DA ANPAD, 33., 2009, São Paulo. Anais... São Paulo: Anpad, 2009.
LASSANCE, Maria Célia Pacheco. Adultos com dificuldade de ajustamento no trabalho: ampliando o quadro da orientação vocacional de abordagem evolutiva. Revista Brasileira de Orientação Profissional, Florianópolis, v. 6, n. 1, p. 41-51, 2006.

LIMA, Gustavo Simão; CARVALHO NETO, Antônio; TANURE, Betânia. Executivos jovens e seniores no topo da carreira: conflitos e complementariedades. REAd, Porto Alegre, v. 71, n. 1, p. 63-96, jan./abr. 2012.

MELO-SILVA, Lucy Leal; LASSANCE, Maria Célia Pacheco; SOARES, Dulce Helena Penha. A orientação profissional no contexto da educação e do trabalho. Revista Brasileira de Orientação Profissional, Florianópolis, v. 5, n. 2, p. 31-52, 2004.

NORONHA, Ana Paula Porto; AMBIEL, Rodolfo Augusto Matteo. Orientação profissional e vocacional: análise da produção científica. PSICO-USF, São Paulo, v. 11, n. 1, p. 75-84, 2006.

PEREIRA, Aline Lucena Costa; SILVA, Anielson Barbosa da. As Competências Gerenciais nas Instituições Federais de Educação Superior. Cadernos EBAPE.BR, Rio de Janeiro, v. 9, p. 627-647, 2011.

PINTO, Joana Carneiro; TAVEIRA, Maria do Céu. Developing carrer self-managment skills: a sudy in higher education. The International Journal of Managment Science and Information Technology, v. 8, p. 25-53, 2013.

RAMPAZZO, Lucas. Metodologia científica para alunos dos cursos de graduação e pós-graduação. 3. ed. São Paulo: Edições Loyola, 2005.

REIS, Germano Glufke. Da experiência ao aprendizado: a prática reflexiva como recurso no processo de coaching de executivos. Revista de Carreiras e Pessoas, São Paulo, v. 3, n. 3, p. 34-48, 2013. 
$\mathrm{RICH}$, Carole. Writing and reporting news: a coaching method. [S.1.]: Cengage Learning, 2015.

SCHEIBLE, Alba Couto Falcão; BASTOS, Antônio Virgílio Bittencourt; RODRIGUES, Ana Carolina de Aguiar. Comprometimento e entrincheiramento: integrar ou reconstruir? uma exploração entre as relações entre estes constructos à luz do desempenho. Revista de Administração R. Adm, São Paulo, v. 48, n. 3, p. 530-543, 2013.

SILVA, Ana Daniela; TAVEIRA, Maria do Céu; RIBEIRO, Eugénia. Mudanças no self de carreira em estudantes universitários. Paidéia Online, São Paulo, v. 19, n. 44, p. 283-292, 2009.

SOUZA, Laura Viela e; SCORSOLINI-COMIN, Fábio. Aconselhamento de carreira: uma apreciação construcionista social. Revista Brasileira de Orientação Profissional, Florianópolis, v. 12, n. 1, p. 49-60, 2011.

SPARTA, Mônica. O desenvolvimento da orientação profissional no Brasil. Revista Brasileira de Orientação Profissional, Florianópolis, v. 4, n. 1, p. 1-11, 2003.

SPARTA, Mônica; BARDAGI, Marúcia Patta; TEIXEIRA, Marco Antônio P. Modelos e instrumentos de avaliação em orientação profissional: perspectivas históricas e situação no Brasil. Revista Brasileira de Orientação Profissional, Florianópolis, v. 7, n. 2, p. 19-32, 2006.

VELOSO, Elza Fátima Rosa; DUTRA, Joel Souza. Carreiras sem fronteiras na gestão pessoal da transição profissional: um estudo com ex-funcionários de uma instituição privatizada. Revista de Administração Contemporânea, Rio de Janeiro, v. 15, n. 5, p. 834-854, 2011.

VELOSO, Elza Fátima Rosa; DUTRA, Joel Souza; NAKATA, Lina Eiko. Percepção Sobre carreiras inteligentes: diferenças entre as gerações $\mathrm{Y}$, X e Baby Boomers. REGE: Revista de Gestão FEA-USP, São Paulo, v. 23, n. 2, p. 88-98, 2016. 